\title{
Plasminflammation-An Emerging Pathway to Bradykinin Production
}

\author{
Coen Maas* \\ Department of Clinical Chemistry and Haematology, University Medical Center Utrecht, Utrecht University, Utrecht, \\ Netherlands
}

Plasminogen activation is essential for fibrinolysis - the breakdown of fibrin polymers in blood clots. Besides this important function, plasminogen activation participates in a wide variety of inflammatory conditions. One of these conditions is hereditary angioedema ( $\mathrm{HAE})$, a rare disease with characteristic attacks of aggressive tissue swelling due to unregulated production and activity of the inflammatory mediator bradykinin. Plasmin was already implicated in this disease decades ago, but a series of recent discoveries have made it clear that plasmin actively contributes to this pathology. Collective evidence points toward an axis in which the plasminogen activation system and the contact system (which produces bradykinin) are mechanistically coupled. This is amongst others supported by findings in subtypes of HAE that are caused by gain-of-function mutations in the genes that respectively encode factor XII or plasminogen, as well as clinical experience with the antifibrinolytic agents in HAE. The concept of a link between

\section{OPEN ACCESS}

Edited by:

Robert Lindsay Medcalf, Monash University, Australia

Reviewed by:

Sidney Strickland,

The Rockefeller University,

United States

Christian Drouet,

INSERM U1016 Institut

Cochin, France

*Correspondence:

Coen Maas

cmaas4@umcutrecht.nl

Specialty section:

This article was submitted to

Molecular Innate Immunity,

a section of the journal

Frontiers in Immunology

Received: 07 May 2019 Accepted: 13 August 2019 Published: 27 August 2019

Citation:

Maas C (2019)

Plasminflammation-An Emerging

Pathway to Bradykinin Production.

Front. Immunol. 10:2046.

doi: 10.3389/fimmu.2019.02046 plasminogen activation and the contact system helps us to explain the inflammatory side effects of fibrinolytic therapy, presenting as angioedema or tissue edema. Furthermore, these observations motivate the development and characterization of therapeutic agents that disconnect plasminogen activation from bradykinin production.

Keywords: plasmin, bradykinin, angioedema, contact system, factor XII

\section{INTRODUCTION}

\section{Plasminogen Activation: More Than "Just" Fibrinolysis?}

The main purpose of plasminogen activation is to break down fibrin in blood clots. Hereto, tPA (tissue-type plasminogen activator) from endothelial cells binds to fibrin. Next, tPA activates adjacent plasminogen molecules which cleave fibrin. Alternatively, the urokinase system can generate plasmin. Hereto, uPA (urokinase type-plasminogen activator) binds to a dedicated receptor (UPAR) on activated endothelial cells, circulating cells (e.g., monocytes), and tissueresident cells. Interestingly, uPAR expression can take place in situations that are unrelated to fibrinolysis. For example, endothelial cells can sense hypoxia and express UPAR in response (1). Alternatively, there is a proposed role for VEGF-induced uPAR expression in angiogenesis (2). Furthermore, uPAR expression is strongly upregulated at sites of inflammation (3), indicating that plasmin has roles beyond fibrinolysis.

\section{The Contact System: More Than "Just" Coagulation?}

The contact system consists of factor XII (FXII), plasma prekallikrein (PK) and high-molecular weight kininogen (HK). These factors assemble on (negatively) charged particles and polymers to generate enzymatic activity. The contact system owes its name to the clotting response that follows when blood contacts surface materials, such as the diagnostic coagulation reagent kaolin. Since its discovery, it has become clear that the contact system is a driving force behind thrombosis 
and hemoincompatibility (4). Remarkably, deficiency in contact factors does not translate into bleeding disorders (5-7), suggesting that a function beyond hemostasis justifies the existence of this enzyme system.

During contact activation, FXII and PK activate each other through reciprocal cleavage into FXIIa and PKa. C1-inhibitor (C1-INH) controls both enzymes. HK is essential to this reaction, as it connects PK to the surface. Truncation of full-length FXIIa $(\alpha$ FXIIa) by PKa into $\beta$ FXIIa eliminates its clotting potential. However, $\beta$ FXIIa remains an excellent fluid-phase PK activator (8). Most information on contact system activation in vitro strongly suggests that FXII activation requires a surface. However, clinical observations point toward to a complimentary mechanism for FXII activation, dissimilar from classical surfacebound contact activation.

\section{Links Between Plasminogen Activation and Contact Activation (Figure 1)}

FXII is strikingly homologous to tPA (Figure 2). They both contain kringle domains, epidermal growth factor-like domains, as well as fibronectin-type I domains. To a certain extent, FXII and tPA are biochemically inter-exchangeable. In 1972, it was reported that FXIIa can act as a plasminogen activator (9). More recently, it was reported that fibrin-bound polyphosphate polymers amplify this reaction (10). There is some clinical evidence supporting the role of FXIIa as plasminogen activator: FXII-deficient human subjects have a lowered capacity for plasminogen activation in response to systemically administered desmopressin (activates endothelial cells) (11). Future studies are needed to disentangle the seemingly conflicting roles of FXII as clotting factor and plasminogen activator.
Conversely, plasmin can also act as a FXII activator. In 1971, it was identified that plasmin can activate FXII into FXIIa (12). We recently confirmed this (13). However, the original biochemical observation remained without consequence for decades. This is largely attributable to the fact that $\mathrm{PKa}$ is a much more competent FXII activator than plasmin is. Plasmin can also act as a direct and reciprocal PK activator, and accelerates bradykinin release from HK (14). Together, these biochemical links between plasminogen activation and the contact system make it attractive to speculate that in the very early stages of in vivo contact activation, when $\mathrm{PKa}$ has yet to become activated; plasmin has an initiating role. Lessons from human pathology, such as hereditary angioedema and neuroinflammation, suggest that this might be the case.

\section{HEREDITARY ANGIOEDEMA}

\section{C1 Inhibitor Deficiency}

Hereditary angioedema (HAE) is a rare disease with characteristic swelling of the deep skin and mucosa caused by local vascular leakage. The onset of tissue swelling attacks is highly unpredictable, but reported triggers include physical exertion, mental stress, mechanical trauma and infections (15). Experienced patients report prodromal symptoms; telltale signs that an attack is imminent (16). Most notably, these patients may have erythema marginatum, a nonpruritic rash that presents gradually (17) and can become clinically apparent very early in life (18).

HAE was first clinically identified in 1888 (19), and connected to $\mathrm{C} 1$ inhibitor deficiency in 1963 (20). The associated disease is now called HAE-C1-INH (OMIM \# 106100) and affects 1:50,000 people. To date, 488 mutations have been identified

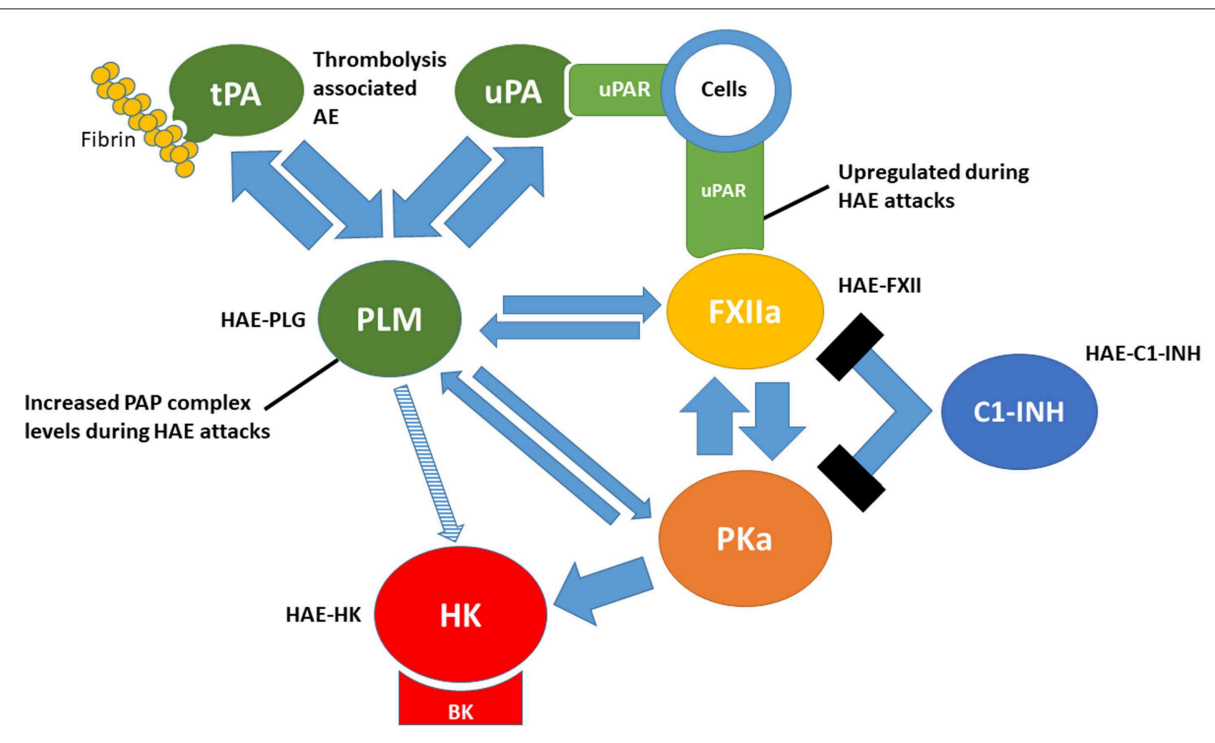

FIGURE 1 | Links between the plasminogen activation and contact activation. tPA, tissue-type plasminogen activator; uPA, urokinase-type plasminogen activator; UPAR, urokinase-type plasminogen activator receptor; PLM, plasmin; FXIla, activated factor XII; PKa, plasma kallikrein; HK, high molecular-weight kininogen; BK, bradykinin; C1-INH, C1 inhibitor. PAP, plasmin- $\alpha 2$-antiplasmin. HAE-PLG, HAE-FXII, HAE-C1-INH and HAE-HK represent forms of hereditary angioedema related to gain-offunction mutations in each factor. 


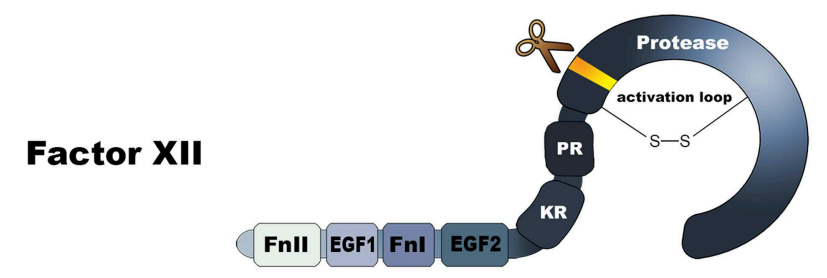

tPA

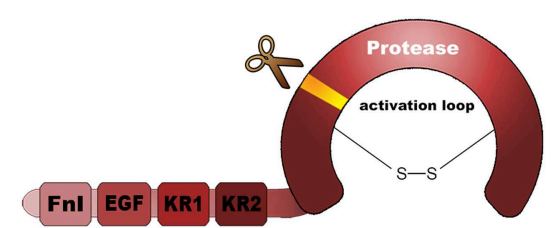

FIGURE 2 | Domain architectures of factor XII and tissue-type plasminogen activator. Fnl, Fibronectin type I domain; Fnll, Fibronectin type II domain; EGF, epidermal growth factor-like domain; KR, Kringle. Both molecules contain a protease domain that becomes active after molecular scission, resulting in an two-chain disulfide-linked molecule.

that cause HAE-C1INH (http://www.hgmd.cf.ac.uk). Some of these are de novo mutations (21). There are two subtypes: quantitative deficiency (type I) and qualitative deficiency (type II). Interestingly, in some heterozygous type I HAE-C1-INH carriers, $\mathrm{C} 1$-INH expression levels that are far below the expected $50 \%$. For a subset of these mutations, there is an explanation: the mutation causes $\mathrm{C} 1-\mathrm{INH}$ to form intracellular aggregates, which incorporate "healthy" wild type C1-INH as well and prevent secretion (22).

In search for the disease mediator in HAE, it was initially thought that unregulated complement activation caused the tissue swelling attacks. Around the same time, it was suggested that $\mathrm{PKa}$ activity was involved in the disease phenotype (23). However, it took decades to directly identify bradykinin as central mediator $(24,25)$. At present, a variety of therapeutic strategies are available that have the aim to reduce bradykinin production, including $\mathrm{C} 1$-INH replacement therapy, or monoclonal antibodies and oral therapies that target and control PKa $(26,27)$.

There are two receptors for bradykinin (and Lys-bradykinin, which is generated by tissue kallikreins): the kinin B2- and $\mathrm{B} 1$ receptors $(\mathrm{kB} 2 \mathrm{R}$ and $\mathrm{kB} 1 \mathrm{R}$, respectively). Whereas $\mathrm{kB} 2 \mathrm{R}$ is constitutively present on the vascular endothelium, $\mathrm{kB1R}$ is expressed by cells at sites of infection and inflammation. KB2R mainly recognizes full-length (lys-)bradykinin. Removal of the C-terminal lysine from (lys-)bradykinin by soluble carboxypeptidase $\mathrm{N}$ or membrane-bound carboxypeptidase $\mathrm{M}$, generates a sequence that is preferred by $\mathrm{kB1}$. Endothelial $\mathrm{kB} 2 \mathrm{R}$ activation induces cytoskeletal rearrangements, uncoupling of tight junctions and triggers NO production, which instructs underlying endothelial cells to relax. A direct, small molecule inhibitor of $\mathrm{kB} 2 \mathrm{R}$ has therapeutic value during acute attacks, showing that the interaction between full length (lys-)bradykinin and $\mathrm{kB} 2 \mathrm{R}$ is key to $\mathrm{HAE}$ pathology (28).

The mechanism behind the localized presentation of the clinical symptoms in HAE is of high interest. It has been proposed that a currently unidentified trigger incites systemic contact activation. Excessive localized vascular leakage is a consequence of locally increased cellular kB1R presentation (29). Indeed, there is evidence for activation products of contact activation during (30), and before the onset of attacks (31). On the other hand, the localized detection of bradykinin at the site swelling (32), together with its limited circulating half-life suggest that bradykinin production is a localized process (33).

\section{PLASMINFLAMMATION: PLASMIN IN HAE-C1-INH}

Plasminogen activation is seen during attacks of HAE-C1INH (34-38). It remains a question what triggers and drives this plasminogen activation. It can be speculated that it is secondary to bradykinin-driven endothelial cell activation, which is accompanied by release of plasminogen activators (39) and depletion of PAI-1 (40). Alternatively, marker for coagulation are also increased in HAE patients: thrombin-antithrombin complex levels, prothrombin fragment $1+2$ and D-dimer levels are all increased $(36,41)$. This suggests that coagulation is first triggered when plasma leaks into the extravascular space, which in turn triggers plasmin formation. However, a study in HAE patient shows that $\mathrm{C} 1-\mathrm{INH}$ replacement therapy lowers $\mathrm{F} 1+2$ levels, while fibrinolytic parameters remain elevated (42). This suggests that plasminogen activation during HAE-C1INH attacks is unrelated to its role in "normal" fibrinolysis.

Interestingly, circulating peripheral blood cells of $\mathrm{C} 1-\mathrm{INH}$ deficient patients express increased amounts uPAR during swelling attacks (43). Furthermore, these patients benefit from prophylactic treatment with the antifibrinolytic agent tranexamic acid, which reduces both the frequency and severity of HAE attacks (44). Finally, careful in vitro studies show that C1-INHdeficient plasma generates excessive amounts of bradykinin when tPA is added (45). This occurs in a FXII and PKa-dependent manner. These combined observations suggests that plasmin has an active role in the pathogenesis of HAE-C1-INH.

\section{Hereditary Angioedema With Normal C1-INH Activity}

Not all forms of HAE are attributable to C1-INH deficiency: there are cases in which patient families experience tissue swelling attacks while both levels and activity of C1-INH are normal (46). These together are classified as type III HAE (OMIM \# 610618). So far, there are four individual forms (47). Below, I will highlight three of those that may be linked:

\section{HAE-FXII}

This form is caused by mutations in the F12 gene (encodes FXII). It was first identified in 2006 in a genetic study under HAE patients with normal C1-INH activity (48), and connected to increased spontaneous FXII activity in plasma (49). Since 
then, five separate mutations have been found that give the same phenotype (50). These patients are often female, and respond well to $\mathrm{kB} 2 \mathrm{R}$ antagonism, as well as tranexamic acid. This indicates that, also in these patients, bradykinin is the responsible disease mediator and that plasmin contributes to pathogenesis. On protein sequence level, these mutations are all located the proline-rich region of FXII. This unstructured and flexible sequence connects the surface-binding domains of FXII to its protease domain (51). Investigations into the underlying disease mechanisms showed us that mutations c.1032C $>$ A (results in $\mathrm{T} 309 \mathrm{~K}$ in the mature protein) and $\mathrm{c} .1032 \mathrm{C}>\mathrm{G}$ (results in T309R in the mature protein) both eliminate an O-linked glycosylation site from the proline-rich region (52). This enhances activation by the anionic polymer dextran sulfate. However, C1-INH inhibits both these FXIIa mutants with the same efficiency as it can inhibit wild type FXIIa. In other words, these mutants are not resistant against inhibition. In further studies, we identified that the replacement of the threonine $(\mathrm{T})$ residue at position 309 with a positively charged arginine $(\mathrm{R})$ or lysine $(\mathrm{K})$ residue introduces putative cleavage sites for trypsin-like serine proteases (13). The same holds true for mutation c.971_1018 + 24del72 (this replaces an existing sequence with a new one that contains 5 arginines). Although $\mathrm{PKa}$ is essential to the activation and subsequent processing of normal wild type FXII, we found that it did not cleave at the putative newly introduced cleavage sites. We next considered plasmin as a candidate enzyme as it A) has the ability to directly activate FXII; B) is active in HAE-C1-INH and C) tranexamic acid has value for HAEFXII (53). We found that plasmin indeed cleaves these three pathogenic forms of FXII at the mutated positions, separating the surface binding domains from the protease domain (13). The resulting fragment is in many aspects similar to $\beta$ FXIIa, but in this case, it has not yet been activated (i.e., it should be called $\beta$ FXII). However, this truncating event leads FXII to expose its activation loop, leaving it highly sensitive to activation by PKa or plasmin in solution (54). In similar manner, others have more recently found that FXII mutants T309K and T309R can also be truncated by thrombin and FXIa (55). This sets the stage for swelling attacks after injury in HAEFXII patients. There are two more mutations in FXII that cause HAE: c.892_909dup (duplicates residues 279-284 in mature FXII) and c.1027G $>$ C (A324P in mature FXII). We found that these are not susceptible to truncation by plasmin (unpublished findings) and it currently remains unclear how these mutations cause pathology.

\section{HAE-PLG}

Very recently, Bork et al. identified a mutation in the plasminogen gene through wholeexome sequencing studies in German patient families that have HAE with normal C1INH activity. The mutation c.9886A $>\mathrm{G}$ causes an amino acid substitution in kringle 3 (K311E; mature protein) (56). The interesting thing about this mutation is that it should restore the lysine-binding properties of kringle 3 that are normally lacking in this human plasminogen kringle (57). It is of high interest and clinical relevance to elucidate how this mutation translates into the seemingly selective clinical phenotype of recurrent angioedema, rather than a bleeding diathesis (this is the picture of hyperfibrinolysis). Conversely, it is interesting that $\alpha 2-$ antiplasmin deficiency (hyperfibrinolysis) does not appear to be accompanied by attacks of tissue edema.

Since the first report on HAE-PLG, the very same mutation has been found in patients from Japan (58), Bulgaria, Spain, Greece (59) and another German patient family (60). Germenis et al. also pointed out that the mutation may not cause disease purely in a stand-alone manner: several patients in their study had additional polymorphisms in the plasminogen gene or alternatively in enzymes that are involved in bradykinin metabolism (59). Not completely surprisingly, these patients respond well to prophylactic treatment with tranexamic acid, indicating that lysine-dependent target engagement of mutant plasminogen is a critical step in the disease mechanism. More importantly, HAE-PLG patients that experience acute attacks respond well to the $\mathrm{kB} 2 \mathrm{R}$ antagonist icatibant, suggesting that bradykinin is an important disease mediator during swelling attacks (60).

\section{HAE-HK}

Even more recently, a new form of HAE with normal C1-INH was identified in a family with a mutation in the KNG1 gene (c.1136T>A; p.Met379Lys). This gene encodes HK, as well as the splice variant low-molecular weight kininogen (LK). The mutation is located in close vicinity to the physiological $\mathrm{N}$ terminal cleavage sites that normally mediates (lys-)bradykinin liberation from its precursor protein, and therefore highly likely to change the release kinetics of bradykinin-based vasoactive peptides. This exciting discovery leads to many questions. Does this mutation selectively affects the release of bradykinin by $\mathrm{PKa}$, or the release of lys-bradykinin by tissue kallikreins? Does the sequence Lys-lys-bradykinin (or its des-Arg metabolite) react normally with $\mathrm{kB} 2 \mathrm{R}$ and $\mathrm{kB} 1 \mathrm{R}$ ?

\section{IMPLICATIONS FOR THE BRAIN}

Tissue swelling and edema formation are general features of both chronic and acute inflammation. In a surprisingly broad and growing spectrum of diseases beyond HAE, bradykinin has been implicated as a disease mediator. For example, FXII-dependent bradykinin production is held responsible for impairment of the blood-brain barrier in Alzheimer's disease. It has been repeatedly found that aggregated amyloid $\beta$ peptide can directly trigger FXII, leading to PKa activity and targeting of this inflammatory pathway has therapeutic value in models for this disease (61-63). Interestingly, experimental knockdown of C1-INH expression in mouse studies recapitulates many of these neurological features without the apparent involvement of amyloid $\beta$ peptide. This suggests that proper control over bradykinin production is essential for a healthy blood-brain barrier in general (64), and might relate to the signs of depression that are reported in HAE patients $(65,66)$.

So how does plasmin fit into this picture? Targeting plasminogen expression in mouse models for Alzheimer's disease attenuates disease progression similar to knockdown of FXII (67). In similar manner, LPS-triggered neuroinflammation 
is attenuated in mice that lack plasminogen or tPA (68). The other way around, experimental induction of sustained hyperfibrinolysis by system overexpression of plasminogen activators in mice leads to increased permeability of the bloodbrain barrier (69). This is attributable to plasmin-driven bradykinin production, fitting with the clinical observation that bradykinin-driven angioedema is a rare (1-5\%) sideeffect of thrombolytic therapy (70). However, brain edema after thrombolytic therapy is much more common and generally considered an unavoidable treatment-associated evil. Interestingly, preclinical studies point out that this phenomenon is actually caused by PKa-driven bradykinin production (71).

\section{THERAPEUTIC TARGETING OF PLASMINFLAMMATION}

Evidently, plasmin-mediated breakdown of blood clots is required for a healthy vasculature; hypofibrinolysis is a risk factor for venous thromboembolism (72). Although prophylactic treatment of HAE patients with antifibrinolytic agents is welltolerated, human plasminogen deficiency is associated with development of ligneous conjunctivitis (73). This suggests that generalized neutralization of plasminogen activation might have adverse effects. Considering that the urokinase system can mediate plasminogen activation in a fibrin-independent manner, it is attractive to speculate that selective targeting of this axis has benefit in repressing excessive plasmindependent bradykinin formation, while tPA remains available for physiological fibrinolysis. Although this a possibility, how about simply targeting the contact factors?

In vivo studies in mouse models, human deficiencies and drug trials have shown us that targeting the contact system is generally safe. However, it should be remembered that there is a proposed role for FXII-dependent coagulation in thrombus stabilization (74). For blockade of plasminflammation, it would be needed to selectively inhibit the molecular interactions between plasmin(ogen) and FXII or other contact factors. Identification

\section{REFERENCES}

1. Graham CH, Fitzpatrick TE, McCrae KR. Hypoxia stimulates urokinase receptor expression through a heme protein-dependent pathway. Blood. (1998) 1:3300-7.

2. Mandriota SJ, Seghezzi G, Vassalli JD, Ferrara N, Wasi S, Mazzieri R, et al. Vascular endothelial growth factor increases urokinase receptor expression in vascular endothelial cells. J Biol Chem. (1995) 270:9709-16. doi: 10.1074/jbc.270.17.9709

3. Smith HW, Marshall CJ. Regulation of cell signalling by uPAR. Nat Rev Mol Cell Biol. (2010) 11:23-36. doi: 10.1038/nrm2821

4. Maas C, Renne T. Coagulation factor XII in thrombosis and inflammation. Blood. (2018) 131. doi: 10.1182/blood-2017-04569111

5. Girolami A, Ferrari S, Cosi E, Girolami B. Cardiovascular diseases in congenital prekallikrein deficiency. Blood Coagul Fibrinolysis. (2018) 29:1. doi: 10.1097/MBC.0000000000000735

6. Ratnoff OD, Colopy JE. A familial hemorrhagic trait associated with a deficiency of a clot-promoting fraction of plasma. J Clin Invest. (1955) 34:60213. doi: 10.1172/JCI103109 of these interaction sites is of high interest, as these can be used for development of agents (e.g., monoclonal antibodies) that selectively neutralize plasminflammation, while leaving other physiological functions of the involved systems intact.

\section{CONCLUSION}

When combining insights from biochemical studies and clinical observations in rare diseases, it becomes clear that plasminogen activation and the plasma contact system are functionally intertwined. Although the role of FXIIa as plasminogen activator was discovered first, the role of plasmin as contact activator is clinically more apparent. In many states of pathology where FXIIdriven bradykinin production contributes to inflammation, the endogenous FXII activator has yet to be identified. However, more often than not, plasmin is present and ready. Development of strategies to uncouple fibrinolysis from plasmin-triggered bradykinin production should have value for treatment of inflammatory conditions.

\section{AUTHOR CONTRIBUTIONS}

The author confirms being the sole contributor of this work and has approved it for publication.

\section{FUNDING}

CM gratefully acknowledges the Landsteiner Foundation for Blood Transfusion Research (\#LSBR 1520), the Netherlands Thrombosis Foundation (\#201703), and the Netherlands Organization for Scientific Research (NWO, \#TTW:00670785).

\section{ACKNOWLEDGMENTS}

I would like to thank Dr. Steven de Maat for critically reading the manuscript and Ms. Wariya Sanrattana for preparing the artwork.
7. Zhang H, Liu S, Lin C, Luo S, Yang L, Jin Y, et al. Compound heterozygous mutations Glu502Lys and Met527Thr of the FXII gene in a patient with factor XII deficiency. Hematology. (2019) 24:420-5. doi: 10.1080/16078454.2019.1598679

8. Revak SD, Cochrane CG, Bouma BN, Griffin JH. Surface and fluid phase activities of two forms of activated Hageman factor produced during contact activation of plasma. J Exp Med. (1978) 147:719-29. doi: $10.1084 /$ jem.147.3.719

9. Kaplan AP, Austen KF. The fibrinolytic pathway of human plasma. Isolation and characterization of the plasminogen proactivator. J. Exp. Med. (1972) 136, 1378-93.

10. Mitchell JL, Lionikiene AS, Georgiev G, Klemmer A, Brain C, Kim PY, et al. Polyphosphate colocalizes with factor XII on platelet-bound fibrin and augments its plasminogen activator activity. Blood. (2016) 128:2834-45. doi: 10.1182/blood-2015-10-673285

11. Levi M, Hack CE, de Boer JP, Brandjes DP, Büller HR, ten Cate JW. Contact system dependent fibrinolytic activity in vivo: observations in healthy subjects and factor XII deficient patients. Agents Actions. (1992) 38(Pt 2):292-8.

12. Kaplan AP, Austen KF. A prealbumin activator of prekallikrein. II Derivation of activators of prekallikrein from active Hageman factor by 
digestion with plasmin. J Exp Med. (1971) 133:696-712. doi: 10.1084/jem.13 3.4.696

13. de Maat S, Björkqvist J, Suffritti C, Wiesenekker CP, Nagtegaal W, Koekman A, et al. Plasmin is a natural trigger for bradykinin production in patients with hereditary angioedema with factor XII mutations. J Allergy Clin Immunol. (2016) 138:1414-23.e9. doi: 10.1016/j.jaci.2016.02.021

14. Kleniewski J, Blankenship DT, Cardin AD, Donaldson V. Mechanism of enhanced kinin release from high molecular weight kininogen by plasma kallikrein after its exposure to plasmin. J Lab Clin Med. (1992) 120:129-39.

15. Zotter Z, Csuka D, Szabó E, Czaller I, Nébenführer Z, Temesszentandrási $\mathrm{G}$, et al. The influence of trigger factors on hereditary angioedema due to C1-inhibitor deficiency. Orphanet J Rare Dis. (2014) 9:44. doi: 10.1186/1750-1172-9-44

16. Maas C. The Protease Storm of Angioedema. J Angioedema. (2013) 1:18-27.

17. Rasmussen ER, de Freitas PV, Bygum A. Urticaria and prodromal symptoms including erythema marginatum in danish patients with hereditary angioedema. Acta Derm Venereol. (2016) 96:373-6. doi: 10.2340/00015555-2233

18. Martinez-Saguer I, Farkas H. Erythema marginatum as an early symptom of hereditary angioedema: case report of 2 newborns. Pediatrics. (2016) 137:e20152411. doi: 10.1542/peds.2015-2411

19. Osler W. Landmark publication from the american journal of the medical sciences. Am J Med Sci. (2010) 339:175-8. doi: 10.1097/MAJ.0b013e3181b2803f

20. Donaldson VH, Evans RR. A biochemical abnormality in herediatry angioneurotic edema: absence of serum inhibitor of C' 1-esterase. Am J Med. (1963) 35:37-44. doi: 10.1016/0002-9343(63)90162-1

21. Bafunno V, Divella C, Sessa F, Tiscia GL, Castellano G, Gesualdo L, et al. De novo homozygous mutation of the $\mathrm{C} 1$ inhibitor gene in a patient with hereditary angioedema. J Allergy Clin Immunol. (2013) 132:748-50.e3. doi: 10.1016/j.jaci.2013.04.006

22. Haslund D, Ryø LB, Seidelin Majidi S, Rose I, Skipper KA, Fryland T, et al. Dominantnegative SERPING1 variants cause intracellular retention of C1 inhibitor in hereditary angioedema. J Clin Invest. (2018) 129:388-405. doi: 10.1172/JCI98869

23. Landerman NS, webster ME, Becker EL, Ratcliffe HE. Hereditary angioneurotic edema. II. Deficiency of inhibitor for serum globulin permeability factor and/or plasma kallikrein. J. Allergy. (1962) 33:330-41. doi: 10.1016/0021-8707(62)90032-1

24. Nussberger J, Cugno M, Amstutz C, Cicardi M, Pellacani A, Agostoni A. Plasma bradykinin in angio-oedema. Lancet. (1998) 351:1693-7. doi: 10.1016/S0140-6736(97)09137-X

25. Nussberger J, Cugno M, Cicardi M, Agostoni A. Local bradykinin generation in hereditary angioedema. J Allergy Clin Immunol. (1999) 104:1321-2. doi: 10.1016/S0091-6749(99)70030-8

26. Aygören-Pürsün E, Bygum A, Grivcheva-Panovska V, Magerl M, Graff J, Steiner UC, et al. Oral plasma kallikrein inhibitor for prophylaxis in hereditary angioedema. N Engl J Med. (2018) 379:352-62. doi: 10.1056/NEJMoa1716995

27. Banerji A, Busse P, Shennak M, Lumry W, Davis-Lorton M, Wedner HJ, et al. Inhibiting plasma kallikrein for hereditary angioedema prophylaxis. $\mathrm{N} \mathrm{Engl} \mathrm{J}$ Med. (2017) 376:717-28. doi: 10.1056/NEJMoa1605767

28. Cicardi M, Banerji A, Bracho F, Malbrán A, Rosenkranz B, Riedl M, et al. Icatibant, a new bradykinin-receptor antagonist, in hereditary angioedema. N Engl J Med. (2010) 363:532-41. doi: 10.1056/NEJMoa0906393

29. Hofman ZLM, Relan A, Zeerleder S, Drouet C, Zuraw B, Hack CE. Angioedema attacks in patients with hereditary angioedema: local manifestations of a systemic activation process. J Allergy Clin Immunol. (2016) 138:359-66. doi: 10.1016/j.jaci.2016.02.041

30. Hofman Z, de Maat S, Suffritti C, Zanichelli A, van Doorn C, Veszeli $\mathrm{N}$, et al. Cleaved kininogen as a biomarker for bradykinin release in hereditary angioedema. J. Allergy Clin. Immunol. (2017) 140:1700-3.e8. doi: 10.1016/j.jaci.2017.07.012

31. Luyasu S, Charignon D, Ponard D, Drouet C, Ghannam A. Angioedema: systemic activation process during prodromes. Ann Allergy Asthma Immunol. (2018) 121:248-9. doi: 10.1016/j.anai.2018.04.026

32. Nussberger J, Cugno M, Cicardi M. Bradykinin-mediated angioedema. N Engl J Med. (2002) 347:621-2. doi: 10.1056/NEJM200208223470820
33. De Maat S, De Groot PG, Maas C. Contact system activation on endothelial cells. Semin Thromb Hemost. (2014) 40. doi: 10.1055/s-0034-13 95159

34. Cugno M, Hack CE, de Boer JP, Eerenberg AJ, Agostoni A, Cicardi M. Generation of plasmin during acute attacks of hereditary angioedema. J Lab Clin Med. (1993) 121:38-43.

35. Konings J, Cugno M, Suffritti C, ten Cate H, Cicardi M, Govers-Riemslag JWP. Ongoing Contact Activation in Patients with Hereditary Angioedema. PLoS ONE. (2013) 8:e74043. doi: 10.1371/journal.pone.0074043

36. Nielsen EW, Johansen HT, Høgåsen K, Wuillemin W, Hack CE, Mollnes TE. Activation of the complement, coagulation, fibrinolytic and kallikrein-kinin systems during attacks of hereditary angioedema. Scand J Immunol. (1996) 44:185-92. doi: 10.1046/j.1365-3083.1996.d01-298.x

37. Nilsson T, Bäck O. Elevated plasmin-alpha 2-antiplasmin complex levels in hereditary angioedema: evidence for the in vivo efficiency of the intrinsic fibrinolytic system. Thromb Res. (1985) 40:817-21. doi: 10.1016/0049-3848(85)90318-4

38. van Geffen M, Cugno M, Lap P, Loof A, Cicardi M, van Heerde W. Alterations of coagulation and fibrinolysis in patients with angioedema due to C1-inhibitor deficiency. Clin Exp Immunol. (2012) 167:472-8. doi: 10.1111/j.1365-2249.2011.04541.x

39. Joseph K, Tholanikunnel BG, Kaplan AP. Cytokine and estrogen stimulation of endothelial cells augments activation of the prekallikrein-high molecular weight kininogen complex: implications for hereditary angioedema. J Allergy Clin Immunol. (2017) 140:170-6. doi: 10.1016/j.jaci.2016.09.032

40. Csuka D, Veszeli N, Imreh É, Zotter Z, Skopál J, Prohászka Z, et al. Comprehensive study into the activation of the plasma enzyme systems during attacks of hereditary angioedema due to C1-inhibitor deficiency. Orphanet $J$ Rare Dis. (2015) 10:132. doi: 10.1186/s13023-015-0351-5

41. Reshef A, Zanichelli A, Longhurst H, Relan A, Hack CE. Elevated D-dimers in attacks of hereditary angioedema are not associated with increased thrombotic risk. Allergy. (2015) 70:506-13. doi: 10.1111/all.12587

42. Relan A, Bakhtiari K, van Amersfoort ES, Meijers JCM, Hack CE. Recombinant C1-Inhibitor. BioDrugs. (2011) 26:43-52. doi: 10.2165/11599490-000000000-00000

43. Castellano G, Divella C, Sallustio F, Montinaro V, Curci C, Zanichelli A, et al. A transcriptomics study of hereditary angioedema attacks. J Allergy Clin Immunol. (2018) 142:883-91. doi: 10.1016/j.jaci.2018.03.016

44. Wintenberger C, Boccon-Gibod I, Launay D, Fain O, Kanny G, Jeandel PY, et al. Tranexamic acid as maintenance treatment for non-histaminergic angioedema: analysis of efficacy and safety in 37 patients. Clin Exp Immunol. (2014) 178:112-7. doi: 10.1111/cei.12379

45. Charest-Morin X, Hébert J, Rivard G-É, Bonnefoy A, Wagner E, Marceau F. Comparing pathways of bradykinin formation in whole blood from healthy volunteers and patients with hereditary angioedema due to $\mathrm{Cl}$ inhibitor deficiency. Front Immunol. (2018) 9:2183. doi: 10.3389/fimmu.2018. 02183

46. Zuraw BL, Bork K, Binkley KE, Banerji A, Christiansen SC, Castaldo A, et al. Hereditary angioedema with normal $\mathrm{C} 1$ inhibitor function: consensus of an international expert panel. Allergy Asthma Proc. (2012) 33:145-56. doi: 10.2500/aap.2012.33.3627

47. Zuraw BL. Hereditary angioedema with normal C1 inhibitor: Four types and counting. J Allergy Clin Immunol. (2018) 141:884-5. doi: 10.1016/j.jaci.2018.01.015

48. Dewald G, Bork K. Missense mutations in the coagulation factor XII (Hageman factor) gene in hereditary angioedema with normal C1 inhibitor. Biochem Biophys Res Commun. (2006) 343:1286-9. doi: 10.1016/j.bbrc.2006.03.092

49. Cichon S, Martin L, Hennies HC, Müller F, Van Driessche K, Karpushova A, et al. Increased activity of coagulation factor XII (Hageman Factor) causes hereditary angioedema type III. Am J Hum Genet. (2006) 79:1098-104. doi: 10.1086/509899

50. De Maat S, Hofman ZLM, Maas C. Hereditary angioedema: the plasma contact system out of control. J Thromb Haemost. (2018) 16:1674-85. doi: $10.1111 /$ ith. 14209

51. de Maat S, Maas C. Factor XII: form determines function. J Thromb Haemost. (2016) 14:1498-506. doi: 10.1111/jth.13383 
52. Björkqvist J, De Maat S, Lewandrowski U, Di Gennaro A, Oschatz C, Schönig $\mathrm{K}$, et al. Defective glycosylation of coagulation factor XII underlies hereditary angioedema type III. J Clin Invest. (2015) 125. doi: 10.1172/JCI77139

53. Bork K, Wulff K, Witzke G, Hardt J. Treatment for hereditary angioedema with normalC1-INH and specific mutations in the F12 gene (HAE-FXII). Allergy. (2017) 72:320-4. doi: 10.1111/all.13076

54. de Maat S, Clark CC, Boertien M, Parr N, Sanrattana W, Hofman ZLM, et al. Factor XII truncation accelerates activation in solution. J Thromb Haemost. (2019) 17:183-94. doi: 10.1111/jth.14325

55. Ivanov I, Matafonov A, Sun M-F, Mohammed BM, Cheng Q, Dickeson SK, et al. A mechanism for hereditary angioedema with normal C1 inhibitor: an inhibitory regulatory role for the factor XII heavy chain. Blood. (2019) 133:1152-63. doi: 10.1182/blood-2018-06-8 60270

56. Bork K, Wulff K, Steinmüller-Magin L, Braenne I, Staubach-Renz P, Witzke $\mathrm{G}$, et al. Hereditary angioedema with a mutation in the plasminogen gene. Allergy. (2018) 73:442-50. doi: 10.1111/all.13270

57. Christen MT, Frank P, Schaller J, Llinás M. Human plasminogen kringle 3: solution structure, functional insights, phylogenetic landscape. Biochemistry. (2010) 49:7131-50. doi: 10.1021/bi100687f

58. Yakushiji H, Hashimura C, Fukuoka K, Kaji A, Miyahara H, Kaname $\mathrm{S}$, et al. A missense mutation of the plasminogen gene in hereditary angioedema with normal C1 inhibitor in Japan. Allergy. (2018) 73:2244-7. doi: 10.1111/all.13550

59. Germenis AE, Germenis AE, Loules G, Zamanakou M, Psarros F, Gonz $\mathrm{T}$, et al. On the pathogenicity of the plasminogen $\mathrm{K} 330 \mathrm{E}$ mutation for hereditary angioedema. Allergy. (2017) 73:1751-3. doi: 10.1111/all. 13324

60. Recke A, Massalme EG, Jappe U, Steinmüller-Magin L, Schmidt J, Hellenbroich Y, et al. Identification of the recently described plasminogen gene mutation p.Lys330Glu in a family from Northern Germany with hereditary angioedema. Clin. Transl. Allergy. (2019) 9:9. doi: 10.1186/s13601-019-0247-x

61. Chen Z-L, Revenko AS, Singh P, MacLeod AR, Norris EH, Strickland S. Depletion of coagulation factor XII ameliorates brain pathology and cognitive impairment in Alzheimer disease mice. Blood. (2017) 129:2547-56. doi: 10.1182/blood-2016-11-753202

62. Maas C, Govers-Riemslag JWP, Bouma B, Schiks B, Hazenberg BPC, Lokhorst $\mathrm{HM}$, et al. Misfolded proteins activate Factor XII in humans, leading to kallikrein formation without initiating coagulation. J Clin Invest. (2008) 118:3208-18. doi: 10.1172/JCI35424

63. Zamolodchikov D, Chen Z-L, Conti BA, Renné T, Strickland S. Activation of the factor XII-driven contact system in Alzheimer's disease patient and mouse model plasma. Proc Natl Acad Sci USA. (2015) 112:4068-73. doi: 10.1073/pnas.14237 64112

64. Farfara D, Feierman E, Richards A, Revenko AS, MacLeod RA, Norris $\mathrm{EH}$, et al. Knockdown of circulating $\mathrm{C} 1$ inhibitor induces neurovascular impairment, glial cell activation, neuroinflammation, and behavioral deficits. Glia. (2019) 67:1359-73. doi: 10.1002/glia.23611
65. Fouche AS, Saunders EFH, Craig T. Depression and anxiety in patients with hereditary angioedema. Ann Allergy Asthma Immunol. (2014) 112:371-5. doi: 10.1016/j.anai.2013.05.028

66. Salemi M, Di Bella F, Miragliotta A, Perricone R, Guarino MD, Cicardi M, et al. Psychological correlates in subjects with Hereditary Angioedema (HAE). J Psychol Psychother. (2014) 4:134. doi: 10.4172/2161-0487.1000134

67. Baker SK, Chen Z-L, Norris EH, Revenko AS, MacLeod AR, Strickland S. Bloodderived plasminogen drives brain inflammation and plaque deposition in a mouse model of Alzheimer's disease. Proc Natl Acad Sci USA. (2018) 115:E9687-96. doi: 10.1073/pnas.1811172115

68. Hultman K, Cortes-Canteli M, Bounoutas A, Richards AT, Strickland S, Norris EH. Plasmin deficiency leads to fibrin accumulation and a compromised inflammatory response in the mouse brain. J Thromb Haemost. (2014) 12:701-12. doi: $10.1111 /$ jth.12553

69. Marcos-Contreras OA, Lizarrondo SM, de, Bardou I, Orset C, Pruvost M, Anfray A, et al. Hyperfibrinolysis increases bloodbrain barrier permeability by a plasmin- and bradykinindependent mechanism. Blood. (2016) 128, 2423-34. doi: 10.1182/blood-2016-03-7 05384

70. Pahs L, Droege C, Kneale H, Pancioli A. A novel approach to the treatment of orolingual angioedema after tissue plasminogen activator administration. Ann Emerg Med. (2016) 68:345-8. doi: 10.1016/j.annemergmed.2016. 02.019

71. Simão F, Ustunkaya T, Clermont AC, Feener EP. Plasma kallikrein mediates brain hemorrhage and edema caused by tissue plasminogen activator therapy in mice after stroke. Blood. (2017) 129:2280-90. doi: 10.1182/blood-2016-09-740670

72. Meltzer ME, Lisman T, de Groot PG, Meijers JCM, le Cessie S, Doggen CJM, et al. Venous thrombosis risk associated with plasma hypofibrinolysis is explained by elevated plasma levels of TAFI and PAI-1. Blood. (2010) 116:113-21. doi: 10.1182/blood-2010-02-267740

73. Magdaleno-Tapial J, Hernández-Bel P, Valenzuela-Oñate C, Gimeno-Ferrer F, Rodríguez-López R, Hernández-Bel L, et al. Congenital plasminogen deficiency with long standing pseudomembranous conjunctival and genital lesions. JAAD Case Rep. (2019) 5:44-6. doi: 10.1016/j.jdcr.2018.09.004

74. Renné T, Pozgajová $M$, Grüner S, Schuh K, Pauer H-U, Burfeind $\mathrm{P}$, et al. Defective thrombus formation in mice lacking coagulation factor XII. J Exp Med. (2005) 202:271-81. doi: 10.1084/jem.200 50664

Conflict of Interest Statement: The author declares that the research was conducted in the absence of any commercial or financial relationships that could be construed as a potential conflict of interest.

Copyright (c) 2019 Maas. This is an open-access article distributed under the terms of the Creative Commons Attribution License (CC BY). The use, distribution or reproduction in other forums is permitted, provided the original author(s) and the copyright owner(s) are credited and that the original publication in this journal is cited, in accordance with accepted academic practice. No use, distribution or reproduction is permitted which does not comply with these terms. 